\title{
A experiência do ser intenso na poesia moderna e a busca pela vida autêntica
}

Adriano Scandolara*

\section{Resumo}

O presente artigo tem como ponto de partida considerações sobre a poesia ocidental moderna como uma arte marcada pela intensidade da experiência singular e pelo ágon contra os limites da linguagem que impõem obstáculos à transmissibilidade dessa experiência. Por meio da aproximação com o discurso místico, sendo o místico o personagem prototípico do contato com o inefável, e com o pensamento de Kierkegaard e Nietzsche sobre o conceito da vida autêntica, pretende-se demonstrar como as dificuldades, as obscuridades e as complexidades dessa poesia, muitas vezes lacônica, fragmentada, enigmática, se alinham, mesmo que não declaradamente, a um discurso que promove a autenticidade por meio da experiência linguística.

Palavras-chave: Autenticidade. Kierkegaard. Nietzsche. Modernidade. Misticismo.

\section{Introdução}

Em seu influentíssimo Depois de Babel, publicado em 1975, o intelectual George Steiner se refere a um conceito que chama de "palavra faltante" (lacking word) ao tratar das questões propostas pelo que entende como "a poesia moderna", i.e. a poesia "difícil" produzida no Ocidente a partir da década de 1870 , num ponto de ruptura que a separa do que chama de "poesia clássica", que abrange não apenas autores da Antiguidade, mas sim tudo que era feito até esse momento. Mas o que Steiner entende por "difícil"? Diz o autor:

\footnotetext{
Bacharel em Letras - Português e Inglês, com ênfase em Estudos da Tradução, pela Universidade Federal do Paraná. Mestre em Letras no programa de Estudos Literários da Universidade Federal do Paraná, sob orientação do Prof. Dr. Rodrigo Tadeu Gonçalves, com bolsa REUNI, e doutor no mesmo programa, sob orientação do Prof. Dr. Caetano Waldrigues Galindo com bolsa CNPq. Tem experiência com os temas: poesia, literatura inglesa, romantismo, modernidade, misticismo, tradução, mito e filosofia da linguagem. E-mail: adrianoscandolara@gmail.com
}

Data de submissão: 09 dez. 2019 - Data de aceite: 07 fev. 2020 http://dx.doi.org/10.5335/rdes.v16i1.10347 
The concept of 'the lacking word' marks modern literature. The principal division in the history of Western literature occurs between the early 1870s and the turn of the century. It divides a literature essentially housed in language from one for which language has become a prison. Compared to this division all preceding historical and stylistic rubrics or movements-Hellenism, the medieval, the Baroque, Neo-classicism, Romanticism-are only subgroups or variants. From the beginnings of Western literature until Rimbaud and Mallarmé (Hölderlin and Nerval are decisive but isolated forerunners), poetry and prose were in organic accord with language. Vocabulary and grammar could be expanded, distorted, driven to the limits of comprehension. (...) But even where it is most explicit, the act of invention, of individuation in Dante's stil nuovo, in the semantic cosmography of Rabelais, moves with the grain of speech (STEINER, 1975, p. 184-5, grifos nossos).

A literatura (especialmente a poesia) do Ocidente deixa de estar confortável com a linguagem e passa a tratá-la como uma prisão. E isso, claro, muda tudo: considerando que a literatura é uma arte feita de linguagem, uma nova postura diante desse material deverá resultar numa forma distinta de tratá-lo. Enquanto o autor confia na linguagem pública, é possível se escorar na tradição e na fala comum, que o une à sua comunidade: é daí que vem a força, segundo Milman Parry, que Steiner cita depois, dos símiles de Homero; e em Shakespeare é isso que permite a manutenção de uma "postura normativa" e da "coerência envolvente" que são a marca dos seus textos.
$\mathrm{Na}$ sequência, temos a análise de trechos de Coriolano (1.10) e Timão de Atenas (4.3), a partir da qual conclui-se que a dificuldade nessas obras, mesmo nos momentos mais obscuros, é sempre de natureza contingente e se desfaz diante de um comentário mais detido. A sintaxe tortuosa, cuja abreviação reflete os saltos lógicos na mente do falante, pode ser esclarecida pela paráfrase, e o vocabulário, por uma visita a um dicionário ou enciclopédia. É o tipo de dificuldade, diz Steiner, que se pode encontrar ao se ler um tratado de química, que não é inerente ao texto. Um leitor suficientemente munido de tempo e materiais para referência, ou com uma edição comentada, não encontrará qualquer problema para compreendê-lo.

E assim prosseguiria a poesia até Goethe e Victor Hugo, os últimos grandes poetas europeus, para Steiner, ainda confortáveis com a linguagem. O cenário muda muito de figura quando surge essa desconfiança do poeta em relação à linguagem. A partir desse momento de ruptura:

The poet no longer has or can confidently hope for tenure in a generalized authority of speech. The languages waiting for him as an individual born into history, into society, into the expressive conventions of his particular culture and milieu, are no longer a natural skin. Established language is the enemy. The poet finds it sordid with lies. Daily currency has made it stale. The ancient metaphors are inert and the numinous energies bone-dry. It is the writer's compelling task, as Mallarmé said of Poe, 'to purify the language of the 
tribe'. He will seek to resuscitate the magic of the word by dislocating traditional bonds of grammar and of ordered space (Mallarmé's 'Un Coup de dés jamais n'abolira le hasard'). He will endeavour to rescind or at least weaken the classic continuities of reason and syntax, of conscious direction and verbal form (Rimbaud's Illuminations). Because it has become calcified, impermeable to new life, the public crust of language must be riven. Only then shall the subconscious and anarchic core of private man find voice (STEINER, 1975, p. 186-7).

Se o poeta se vê diante da língua dos seus conterrâneos e a enxerga como "sórdida de mentiras", como pode esperar encontrar nela respaldo para sua arte? Se ele vê com desprezo a linguagem corrente - e Steiner cita, em nota, os conflitos entre o poeta e a classe média como um dos motivos que alimentam essa ruptura -, como poderá utilizá-la como matéria-prima? Cada vez mais esse vai ser o material não para o poeta, mas para o publicitário, conforme emerge essa modalidade do discurso na sociedade moderna, que irá se apropriar de recursos tradicionais da poesia. O que vai alimentar o poético deverá ser alguma outra coisa, que o poeta precisará buscar longe da praça pública, e é nessa tensão entre alguma comunicabilidade (afinal, o poeta ainda escreve para alguém) e a recusa à comunicação que muito da poesia posterior vai operar. Os termos em que Steiner coloca isso são dramáticos: imagens marcantes como a "crosta pública da linguagem", que se vê "calcificada" e precisa ser "fendida", expressões espiri- tualizadas como "a magia das palavras" e “energias numinosas”. Ele não está tanto racionalizando esse conceito quanto condensando o que parece ser uma ideia recorrente entre os poetas modernos, e o faz de modo consoante com essa visão poética, como se dissesse: tal é a visão que o poeta tem depois de 1880 .

Steiner prossegue então citando exemplos de poemas de Mallarmé, Rilke e Celan. O poema de Mallarmé em questão (o "Soneto Alegórico de Si Mesmo"), diz ele, se debate contra os limites da linguagem. Ainda que os métodos de explicação tradicionais tenham ainda algum grau de eficácia, as obscuridades são de outra natureza, conforme a linguagem trabalha contra o discurso público e se volta introspectivamente. Esse tipo de poesia, como também Khlebnikov e Stefan George bem sabem, no rastro de Mallarmé, opera pelo processo do "fracasso calculado", e revela, em seus escombros, "o poema que poderia ter sido, o poema que será se e quando a palavra for renovada" (STEINER, 1975, p. 190).

Para o crítico Harold Bloom, que publica $A$ angústia da influência - uma teoria da poesia apenas dois anos antes de Depois de Babel, o poema (sobretudo o poema do romantismo em diante, que é o recorte feito por suas análises) é uma coisa igualmente triste, que marca a "tardividade" do seu autor, sua angústia por ter nascido depois dos poetas que o influenciaram: 
A poem is a poet's melancholy at his lack of priority. The failure to have begotten oneself is not the cause of the poem, for poems arise out of the illusion of freedom, out of a sense of priority being possible. But the poem - unlike the mind in creation - is a made thing, and as such is an achieved anxiety (BLOOM, 1973, p. 96).

Entender o poema como uma "angústia realizada", afinal, também não é vê-lo como uma forma de fracasso? A angústia jamais se resolve, ela apenas se cristaliza num objeto mais palpável, que é o poema. Ben Lerner, em seu muito mais recente The Hatred of Poetry, segue curiosamente ainda pela mesma via:

Poetry arises from the desire to get beyond the finite and the historical-the human world of violence and difference-and to reach the transcendent or divine. You're moved to write a poem, you feel called upon to sing, because of that transcendent impulse. But as soon as you move from that impulse to the actual poem, the song of the infinite is compromised by the finitude of its terms. (...) Thus the poet is a tragic figure. The poem is always a record of failure. There is an "undecidable conflict" between the poet's desire to sing an alternative world and, as Grossman puts it, the "resistance to alternative making inherent in the materials of which any world must be composed" (LERNER, 2016, p. 7).

"O poema é sempre um registro de fracasso": o poeta é uma figura trágica, porque é incapaz de trazer sua visão, perfeita e maravilhosa, vinda de sua origem transcendental divina, a esse mundo "corrompido". Mesmo quando não se fala necessariamente em termos de fracasso, como aponta Tezza em Valéry, há uma ideia de destruição presente ainda:

Em Paul Valéry, que passou boa parte da vida também em busca da "voz absoluta", a superioridade da poesia se justificará tecnicamente como uma superioridade operacional nascida sobre os destroços da "linguagem comum" (TEZZA, 2003, p. 66).

Esses são alguns dos paradoxos de um contingente significativo e influente da poesia moderna: ela diz o indizível, mas o diz de uma forma que é difícil de compreender, ela é o uso mais nobre da linguagem, mas os poemas são fracassos e destroços, justamente porque tentam abarcar o que é infinito, inefável, com a finitude da linguagem histórica humana. Dante no Canto XXXII, vv. 7-9, do Inferno, um dos últimos do livro, já lamentava a dificuldade da tarefa complicada de descrever "o fundo do universo" em palavras de uma língua que diz mamma ou babbo, i.e. em italiano, as balbuciações infantis para "mamãe" e "papai" que formam as suas primeiras enunciações.

Voltando a Steiner, o que ele diz de Mallarmé vale ainda para os exemplos de Rilke e Celan, comentados na sequência, dois poetas da língua alemã com técnicas radicalmente diferentes em relação à poética de Mallarmé e entre si, de modo a demonstrar que esse efeito não vale para uma só língua, um idioma (língua $\neq$ linguagem), nem decorre de uma única técnica ou possibilidade poética e que, mesmo quando as palavras encon- 
tram-se "nuas em sua simplicidade", o poema moderno não pode ser elucidado via paráfrase, e o aspecto enigmático persiste, por mais que o poeta se valha de vocabulário e sintaxe pouco rebuscados. O poeta "não busca ser compreendido" (STEINER, 1975, p. 191), e tampouco essa "compreensão tem qualquer influência sobre a causa e a necessidade do poema”, palavras aqui que remetem também às de Walter Benjamin quando, no famoso ensaio "A tarefa do tradutor", descreve a má tradução de poesia, i.e. para ele a tradução mais literal e semântica, como "uma transmissão inexata de um conteúdo inessencial" (BENJAMIN, 2008 , p. 66). Steiner começa a partir desses nomes como os seus primeiros exemplos, depois passa ainda ao Joyce de Finnegans Wake, até chegar aos poetas do dadaísmo, da poesia sonora e letrista principalmente, bem como o Beckett lacônico de sua produção final. Esses autores são listados como os casos mais extremos dessa postura de desconfiança da linguagem, que leva o autor a violá-la e, no limite, a recusar por completo a comunicabilidade e buscar o silêncio.

Já o classicista Paul Veyne também encontra um ponto de ruptura dramático na poesia ocidental moderna, porém, ele o faz de outro modo, em outro momento, identificando-o quase cem anos antes do que seria o ponto de ruptura para Steiner. No encerramento de seu A Elegia Erótica Romana, no capítulo em que trata dos motivos, diz ele, pelos quais a poesia clássica soaria tão "tediosa" aos ouvidos modernos, por sua brandura, Veyne encontra precisamente no romantismo esse momento em que a poesia ocidental substitui a sutileza das artes pela intensidade da expressão (VEYNE, 1985, p. 274). Veyne associa a poética da intensidade a uma pragmática da sinceridade - portanto da expressão do que seria mais verdadeiro, em oposição à insinceridade da retórica, que é vista negativamente - na medida em que "querendo demais ser compreendidos, afirmamos menos intensamente, e, por isso, tornamo-nos insinceros" (VEYNE, 1985, p. 270). Esse caminho, por sua vez, seguindo pela direção contrária, levaria à obscuridade, uma vez que o oposto da retórica seria a produção impensada ou, pelo menos, a sua aparência, em toda sua intensidade e espontaneidade (ainda que seja uma espontaneidade forjada) que, no limite, visa apenas ser, não comunicar e ser compreendida. Nos termos dos pensadores Deleuze e Guattari (1972), esse é o ponto em que a linguagem deixa de ser expressão para tornar-se produção, quando "não se define mais pelo que diz [...] mas pelo que faz correr, fluir e explodir" (p. 159).

Veyne identifica as primeiras e episódicas violações mais fortes da comunicação em Jean-Jacques Rousseau e James Thomson, poeta escocês do século XVIII, violações que seriam impensáveis para 
um poeta da Antiguidade (DELEUZE; GUATTARI, 1972, p. 269). A partir daí temos uma sistematização desse efeito em todo o romantismo - Veyne fala de Shelley também, associado a Byron, mas deveríamos citar ainda seus antecessores Wordsworth e Coleridge. O autor não está preocupado com a questão dos limites da linguagem, mas é possível relacioná-lo a Steiner, porque ambos tratam de obscuridade e violações de comunicação, e porque essa percepção de uma insinceridade retórica pode ser vista como ponto de partida para a percepção da linguagem como prisão.

\section{A experiência poética e o estado místico}

Podemos falar, então, num esquema para compreender esse modo poético de que tratam Veyne e Steiner: o poeta moderno prototípico primeiro passa por uma experiência que lhe parece intensa, como Wordsworth e os seus narcisos em "I wandered lonely as a cloud", por exemplo, e, ao colocar isso em palavras, percebe que o discurso público não dá conta do seu relato - ele o falsifica e mata o que há de interessante e singular nele ao submetê-lo às amarras da gramática e do bom gosto. É preciso encontrar outros modos de expressão, violar a linguagem comum, explodi-la, fragmentá-la, preenchê-la de lacunas, silêncios e imagens chocantes, primeiro de forma mais tímida, em Rousseau, Thomson e nos românticos, depois com mais violência pelos séculos XIX e XX.

Insinua-se assim uma comparação, bastante frutífera, com o discurso místico - e, não por acaso, tanto Steiner quanto Bloom têm suas obras permeadas de referências ao corpus de práticas e leituras do misticismo judaico conhecido como Cabala. A relação entre o misticismo e o inefável já foi bem delineada pelo psicólogo William James. Em sua tentativa de entender o fenômeno do "estado místico", que ele define de forma específica de modo a evitar a vagueza que um termo como "misticismo" pode suscitar, James chega a quatro características definitivas. São elas, como ele as define: inefabilidade, qualidade noética, transitoriedade, passividade. Dentre estas, é evidente que a inefabilidade é a que mais nos interessa. Diz James em suas palestras que culminaram no volume The Varieties of Religious Experience, publicado, originalmente, em 1901:

The handiest of the marks by which I classify a state of mind as mystical is negative. The subject of it immediately says that it defies expression, that no adequate report of its contents can be given in words. It follows from this that its quality must be directly experienced; it cannot be imparted or transferred to others. In this peculiarity mystical states are more like states of feeling than like states of intellect. No one can make clear to another who has never had a certain feeling, in what the quality or worth of it consists. One must have musical ears to know the value of a symphony; one must 
have been in love one's self to understand a lover's state of mind. Lacking the heart or ear, we cannot interpret the musician or the lover justly, and are even likely to consider him weak-minded or absurd. The mystic finds that most of us accord to his experiences an equally incompetent treatment (JAMES, 1917, p. 380)

Gershom Scholem, estudioso da Cabala e do fenômeno do misticismo em geral, escrevendo cerca de meio século após James, também tem algumas coisas relevantes a dizer, seguindo por uma linha semelhante. Ao comentar a diferença entre os tipos de contato com o divino vividos pelo místico e pelo profeta, - duas figuras semelhantes no imaginário popular, mas que apresentam certas nuances em sua relação com o divino - Scholem traça a seguinte distinção:

Estamos claramente lidando com duas categorias diferentes de experiências e duvido muitíssimo que um profeta possa justamente ser chamado de místico. Pois, como afirmamos, a experiência do místico é por sua própria natureza indistinta e inarticulada, enquanto que a mensagem do profeta é clara e específica. De fato, é precisamente o caráter indefinível e incomunicável da experiência mística que é a maior barreira à nossa compreensão dela. Ela não pode simples e totalmente ser traduzida em imagens ou conceitos agudos, e muitas vezes desafia qualquer tentativa - mesmo posteriormente - de supri-la de um conteúdo positivo. Ainda que muitos místicos tenham tentado semelhante "tradução" e tentado dar forma e corpo às suas experiências, o cerne do que um místico tem a dizer sempre permanece uma experiência sem forma, independentemente de nossa opção de interpretá-la como unio mystica ou "mera" comunhão com o divino (SCHOLEM, 1978, p. 19).
É porque "o cerne do que um místico tem a dizer sempre permanece uma experiência sem forma" que falamos em “inefável” para descrever a experiência mística, em oposição à profética, em que se dá a transmissão de mensagens claras ao povo. Qualquer que seja a forma por meio da qual o místico atinge esse tipo de consciência, ela é sempre marcada por essa incapacidade de reduzir sua experiência, aquilo que é visto, ouvido ou sentido, a uma organização lógica racional que possa ser facilmente colocada em palavras - e, como a comunicação depende de certas regras sobre quais palavras podem ser usadas em qual contexto e em qual ordem, ela necessariamente precisa ser intermediada pela razão. Talvez não por acaso, os versos de abertura do Canto XXXII não são a única ocorrência da constatação de Dante de uma inadequação da linguagem humana. Ele retorna a esse lugar-comum em outros momentos ainda, tanto no Inferno quanto no Purgatório (Cantos V, vv. 100-2 e XXXIII, vv. 82-4) e Paraíso (Cantos I, vv. 1-9, XI, vv. 130-2, XI, vv. 1-12, XV, vv. 37-42), o que reforça essas qualidades inefáveis de jornada mística do seu poema.

No contexto histórico europeu, é importante apontar ainda que, paradoxalmente, o Iluminismo do século XVIII foi rico em produzir formas de espiritualidade divergentes da religião tradicional, iconizadas pelas incontáveis sociedades secretas do período (MCINTOSH, 2011, 
p. 18) e pela obra do místico sueco Emanuel Swedenborg, que viria a se tornar popular em meio aos intelectuais e artistas do século XIX (BALAKIAN, 1985, p. 18). De fato, pode-se dizer que o misticismo substitui, entre os românticos, a religião como principal forma de espiritualidade (BALAKIAN, 1985, p. 20). E a palavra-chave aqui, para entender isso, parece ser "intensidade": aquilo que as práticas místicas oferecem e em que se ancoram não é meramente a tradição pela tradição, somada a algum espaço comunitário religioso, mas sim um tipo intenso e inexplicável de experiência. O que define o místico, como vemos em Scholem (1978, p. 18), é a experiência, bastante pessoal e singular, que ele apreende do divino.

Nisso, são exemplos dos mais ilustrativos os de Wordsworth, com poemas como "I wandered lonely as a cloud", na medida em que descreve um tipo radical de experiência da natureza pelo eu-lírico diante de uma imagem (a dos narcisos à beira-mar); de Coleridge, com o seu sonho embalado pelo uso de láudano que gera o famoso poema "Kubla Khan"; de Shelley, com as imagens oníricas de seu Alastor, que foram motivo de perplexidade para a crítica do período; e Blake, com sua complexa mitologia própria. Contra o torpor do cotidiano burguês, o romântico - sempre extremo e avesso a tudo que seja morno (HOBSBAWM, 1962, p. 259-60) - propõe o choque da experiên- cia intensa, seja ela a experiência da contemplação do mundo natural; do amor; da beleza da arte; do Nada; de estados artificialmente alterados de consciência; a experiência mística propriamente ou a experiência puramente mental da imaginação estimulada. A essa intensidade de vida deveria corresponder também uma intensidade de expressão, como comenta Veyne (1985, p. 270), e é essa exploração da intensidade literária que distanciará cada vez mais os artistas dos modos mais racionais e instrumentais de expressão, como o discurso científico, comercial ou jornalístico.

Nesse processo, o poeta e o artista no geral são levados a compor obras cada vez mais originais - a originalidade e seu louvor como um valor positivo, de fato, quase divino, sendo conceitos relativamente recentes na história literária. Marjorie Perloff aponta como a primeira ocorrência da palavra originality, em inglês, data de 1776, da obra Travels in Spain, de H. Swinburne, na qual é um conceito jurídico e não estético, servindo para distinguir uma pintura autêntica de falsificações e pinturas espúrias (PERLOFF, 2013, p. 56). Também Lynch (2006) comenta que um marco na história da originalidade foi o panfleto Conjectures on Original Composition, do poeta Edward Young, publicado em Londres em 1759, no qual Young argumenta que os autores originais são melhores do que os imitadores, porque tudo que um 
imitador faz é produzir uma cópia pior de algo que já existe (YOUNG, 1918, p. xvi). O sucesso em produzir o original é uma prova da singularidade da experiência do poeta - ou ainda das suas sensibilidades em apreender experiências intensas a partir do que, para um não-poeta, seriam eventos mundanos, como diz Blake, em seus "Auguries of Innocence":

To see a World in a Grain of Sand / And a Heaven in a Wild Flower / Hold Infinity in the palm of your hand / And Eternity in an hour (BLAKE, 1988, p. 490).

\section{A busca pela autenticidade}

Há uma conexão, portanto, entre as "dificuldades" oferecidas pela poesia moderna (ou, pelo menos por uma parte significativa desse corpus), por conta de suas violações da linguagem comunicativa do dia a dia, a intensidade de suas experiências, tal como o poeta as percebe, e a originalidade que se torna um imperativo a partir do Romantismo. Porque o poeta abre mão de ser compreendido de formas racionais, ele pode deliberadamente submeter a linguagem a experimentações mais extremas e próprias, constituindo estilos que permitam que um poema seja reconhecível como de autoria deste ou daquele nome, a ponto de certas marcas, como o uso de travessões por Emily Dickinson, passarem a remeter diretamente a esse ou aquele escritor ou escritora. Mas há um conceito maior aqui, em torno do qual todos esses orbitam, que os articula e permite relacioná-los mais intimamente à modernidade - compreendida aqui como as mudanças sociais provocadas pela "era das revoluções", como descreve Hobsbawm (1962), marcada sobretudo pela tríade das revoluções americana, francesa e industrial, cujas consequências, como bem se sabe, foram a industrialização e urbanização que possibilitaram a emergência de grandes metrópoles como Paris e Londres, além de um mercado financeiro poderoso em Wall Street, que fizeram florescer o capitalismo no final do século XIX (HOBSBAWM, 1962).

Esse conceito crucial aqui é o da autenticidade.

Mas, afinal, o que é o autêntico? Vários pensadores célebres já trataram da autenticidade e da vida autêntica: Golomb, em sua obra, trabalha com o conceito em Kierkeegard, Nietzsche, Sartre, Heidegger e Camus (GOLOMB, 1995). A etimologia da palavra é violenta: "autêntico" vem do grego authentikós ( $\alpha \dot{\theta} \theta \varepsilon v \tau \imath \kappa o ́ \varsigma)$, que carrega um sentido ligado a autoridade e cuja raiz authéntēs ( $\alpha$ $\theta \dot{\varepsilon} v \tau\rceil \varsigma)$ se refere não apenas a alguém dotado de poder, mas a alguém que comete atos de violência com as próprias mãos, inclusive autoviolência. Trilling associa essa etimologia poeticamente, por mais que esquecida em seu uso cotidiano, à violência inerente ao ato do 
indivíduo recobrar e impor sua própria vontade numa sociedade treinada para a obediência (TRILLING, 1971), o que poderíamos associar ainda à violência simbólica das transgressões literárias. Golomb, que, nos capítulos de abertura de seu livro, explora exemplos literários de atos de violência (no episódio bíblico de Abraão e Isaac e em $O$ Estrangeiro, de Camus), argumenta que a autoridade da autenticidade é um tipo de autoridade sobre si mesmo, "o domínio daquele que cria livremente o páthos da autenticidade e se esforça para exprimi-lo e vivê-lo no cotidiano" (GOLOMB, 1995, p. 11). Já Taylor é um pouco mais claro em sua definição:

Authenticity is itself an idea of freedom; it involves my finding the design of my life myself, against the demands of external conformity (TAYLOR, 1991, p. 67-8).

Mas o problema, é evidente, é como se faz isso.

Uma das características mais complexas do conceito de autenticidade é que não é possível receber uma lista pronta, um passo a passo, de como ser autêntico, pois o próprio gesto de seguir uma lista pronta para se tornar autêntico seria inautêntico. Ao mesmo tempo, o conceito está tão profundamente arraigado na estética do século XX que, ainda assim, é facilmente transmissível. $\mathrm{O}$ mais fácil - e justamente um dos motivos pelo qual, diz Golomb (1995, p. 45), os autores da autenticidade tender a recorrer à ironia, à via negativa - é descrever o oposto, i.e. a vida inautêntica. O imaginário ocidental moderno concebeu coletivamente imagens da vida inautêntica como uma vida mecânica, que transforma o ser humano numa peça de uma engrenagem, destituído de imaginação e de capacidade de pensar por si próprio, "homens ocos", como diz o poema de Eliot. Esse processo, diagnosticam nossos autores, derivaria da ascensão do capitalismo.

Como diz Taylor, ao comentar as três formas de "mal-estar" (malaise) da modernidade, $o$ individualismo seria uma delas, não por si só, mas pelas suas consequências: antigamente as pessoas se enxergavam como parte de uma ordem maior, uma ordem cósmica que formava uma "grande cadeia do Ser". A liberdade individual só pode ser conquistada libertando-se desses "horizontes morais mais antigos", o que costuma ser visto como uma coisa positiva, porém, como essa ordem maior também servia para dar sentido à vida, algo acabou se perdendo no processo: logo os ideais heroicos, em nome dos quais as pessoas costumavam outrora viver e morrer, são substituídos por prazeres mesquinhos e autocentrados, esvaziados de paixão (TAYLOR, 1991, p. 3). Weber (2004) fala do processo de desencantamento (Entzauberung em alemão) do mundo, o processo de secularização e o declínio da magia, acompanhados da ascensão, em escopo, escala e poder, das racionalidades da 
ciência, burocracia, direito e política (JENKINS, 2000, p. 13), radicalizada na modernidade por conta do ascetismo protestante, que nega tanto as possibilidades da magia quanto a utilidade do ritual, como os sacramentos católicos, para a salvação (SCHLUCHTER, 1981). O mundo desencantado é o mundo que perdeu "todo valor inerente diante de Deus" e pode, portanto, se tornar "o objeto da vontade de Deus" (JENKINS, 2000, p. 171). Como consequência, na medida em que nada mais é sagrado no mundo, indivíduos e materiais são igualmente matéria-prima para produção - o que Deleuze e Guattari descrevem pelo termo "descodificação dos fluxos". Quando chegamos ao capitalismo, dizem os autores, a produção da sociedade deixa de estar ligada ao seu aproveitamento ou mesmo aos excessos de consumo de uma dada classe, mas tem-se a "produção pela produção", que se retroalimenta (DELEUZE; GUATTARI, 1972, p. 266). O Capital, ao qual é atribuída uma função criadora, deixa de ser um meio para se tornar um fim.

A vida mecanizada, assim, é a vida submetida à ordem da razão instrumental e sua busca pela eficácia que norteiam esse éthos capitalista da produção pela produção e consumo pelo consumo. Ao entregar-se a esse sistema, ao deixar de relutar contra ele, o resultado é com frequência tratado em termos de um tipo de morte em vida (TRILLING, 1971, p. 132; GOLOMB, 1995, p. 124), um tema já explorado na poesia dos românticos ingleses como Coleridge, Keats e Shelley (BLOOM, 1971), uma vida no "piloto automático", espiritualmente pobre, insensível às experiências intensas que ocupam a poesia, sendo o indivíduo tão desprovido de personalidade que, como uma peça de fato, pode tranquilamente ser substituído por outro, seja numa empresa, seja numa repartição pública. Ele não precisa refletir, não precisa criar e não precisa pensar em nada que não diga respeito à eficiência de sua função, libertado de toda escolha, inclusive moral - o que vale tanto para uma figura como Adolf Eichmann, o burocrata nazista capturado e julgado em 1960, cujo julgamento foi acompanhado por Hannah Arendt em seu Eichmann em Jerusalém, quanto para os empresários de alto escalão de companhias que ignoram crimes ambientais e violações dos direitos humanos.

Nesse sentido, por contraste, poderíamos concluir que a autenticidade está relacionada a um tipo de "força vital" criativa do indivíduo, em que o ser existe com intensidade e resiste às tentativas do mundo ao seu redor, sobretudo o mundo social, de moldá-lo. Essa resistência, no entanto, não é apenas passiva, reativa, e sim parte de um trabalho ativo de autocriação: o indivíduo autêntico está numa atividade constante de criar o indivíduo singular que é. Falamos em termos 
metafóricos de "força vital", porque, para os filósofos da autenticidade e os autores de que Trilling e Golomb tratam como exemplos de exploração do conceito, esse não é um processo tranquilo, mas um ágon, o oposto disso sendo a passividade fácil da morte em vida. Essa presença do elemento criativo também é responsável por aproximar a autenticidade da arte, pela exploração da originalidade.

Para Golomb, o primeiro pensador no mundo ocidental a refletir sobre o problema da autenticidade foi Kierkegaard, cuja busca por um ideal próprio, só dele, "pelo qual pudesse viver e morrer", como registrado em seu diário em 1835, aos 22 anos, o levou a conceber o livro $\mathrm{Ou}$ isso, ou aquilo (Enten - Eller), publicado em 1843. Seu principal conceito, que lhe dá o título, é o da divisão das possibilidades da vida humana em duas esferas, ou estágios, mutuamente excludentes, aos quais ele opõe ainda uma terceira, que as transcende e que seria a única capaz de se alinhar ao caminho da autenticidade verdadeira. Essas duas esferas incompatíveis são a vida ética e a estética. Sobre a vida estética, resume Golomb (1995), entende-se a palavra em sua acepção mais etimológica, ligada aos sentidos. As paixões do esteta se diluem no objeto estético de maneira passiva, em vez de servirem para motivá-lo a criar a si mesmo. Ele mergulha em prazeres sensoriais e absorção passiva ou em reflexões paralisantes que não dão margem para agir, porque não há espaço no modo de vida estético para a paixão, o tipo de intensidade emocional que só pode ser suscitado pela relação com Deus, o infinito, o inefável. $\mathrm{Na}$ ausência disso, o seu destino é o tédio que ressurge com a repetição incessante dos mesmos estímulos (GOLOMB, 1995).

Tal modo de vida acaba sendo insustentável, portanto, e conduziria apenas à melancolia e ao desespero. Seu oposto, a vida ética, ainda que siga por vias distintas, também leva a esse mesmo destino, no entanto. Na medida em que a ética, como Kierkegaard a compreende, exige uma conformidade que despersonaliza o “eu”, a sua expressão espontânea e apaixonada também acaba comprometida (GOLOMB, 1995). Não há espaço para a criação de si mesmo, porque os valores e aspirações seguem por caminhos já bem estabelecidos por outrem. Além do mais, como essa conformidade se dá em termos de adesão a objetivos idealizados (abstratos, formais e universais) que nunca podem ser cumpridos, ela resulta em sentimentos de culpa pela incapacidade de dar conta do que se é exigido, ao mesmo tempo em que o sentimento de dever eclipsa o amor e a paixão. $\mathrm{O}$ modo ético, então, é só em aparência superior ao estético. A ética em si não se sustenta "sem a paixão da fé", e essa paixão também não pode ser encontrada em objetos estéticos finitos.

Uma comparação com os papéis do indivíduo na modernidade fica sugerida 
ao contemplarmos essas duas formas de vida. Como consumidor de toda sorte de experiências sensoriais, i.e. estéticas, ofertadas pelo capitalismo, ele é treinado a diluir temporariamente sua ansiedade em objetos finitos, sem jamais saciar-se, para que a cadeia de produção contínua seja mantida, mantendo com isso os fluxos e os ritmos cada vez mais intensos da vida moderna. Ao mesmo tempo, como trabalhador é esperado um tipo de subserviência e dever, mesmo que desprovido de paixão, que é típico da vida ética, de modo que, como consumidores e produtores, a vida humana foi tão devidamente compartimentalizada que, pela lógica do pensamento da autenticidade, o que era "Ou isso, ou aquilo" se torna "hora disso" e "hora daquilo", como diz Drummond, em "Nosso Tempo", em sua descrição do horário de almoço: "Come, braço mecânico, alimenta-te, mão de papel, é tempo de comida, / mais tarde será o de amor" (ANDRADE, 2001, p. 38) .

Para Kierkegaard, é preciso buscar um terceiro modo, o religioso, para se seguir o caminho da autenticidade verdadeira. Para uma perspectiva secular contemporânea, essa conclusão pode parecer contraditória, - como é possível ser autêntico como parte das massas obedecendo a dogmas e normas de conduta a fim de não ser expulso da congregação? No entanto, não é a adoção às formas tradicionais do cristianismo como religião organizada que Kierkegaard tem em mente. Pelo contrário, como aponta Golomb, seus exemplos de "cavaleiros da fé", Abraão e Jesus, foram, com efeito, fundadores de religiões, figuras que precisaram "criar Deus". Golomb (1995) se pergunta o porquê de ser apenas o "Deus Absoluto" o único objeto capaz de preencher nossos corações com a paixão necessária para o compromisso da autenticidade. A resposta a que ele chega é a seguinte:

One possible answer to this question, which will perhaps be regarded as scandalous by believers in any version of a transcendent God, is that this kind of faith is an expression of the ultimate paradox and requires man's most sustained creativity. To create God requires the utmost passion possible of man. I do not refer here to an actual creation but to the intentional constitution of the relation to an object which by this very relation becomes the Absolute. In his story of Abraham, Kierkegaard implies that the existential experience, which makes the 'knight of faith' affirm the command subjectively and regard it as coming from God, grants this God the status of being an absolute entity for Abraham. In order for the Absolute to become an Absolute for me and to demand of me 'an absolute duty', this Absolute is completely dependent upon my subjective interpretation of him as the Absolute. Here we reach the climax of the paradox: despite Abraham's awareness that the Absolute is dependent upon his decision to make him so, a fact that may destroy the immediate relation towards him, Abraham acts as if this Absolute has an objective authority to be the Absolute! Though the Absolute depends upon one's subjective decision, one has to accept him, as does Abraham, as if he is the objective Absolute per se. Thus God is intentionally created in our hearts, though we obey him as ontologically aloof, in heaven (GOLOMB, 1995, p. 63). 
Eis, portanto, a Grande Obra das capacidades criativas do ser humano, a demonstração dos poderes plenos da originalidade: a criação de Deus, o que significa, melhor dizendo talvez, a criação de uma relação com Deus. É uma relação diferente da obediência calcada pela lei, pela adesão a um código de normas preestabelecido e posto em prática por outras pessoas em relação a um objeto já bem definido. É preciso que esse objeto infinito, ainda num estágio não plenamente concebido, preencha $o$ indivíduo com paixão, e essa paixão o motive à ação, o motive a criá-lo, o que transforma o indivíduo no processo. Esses termos nos fazem pensar numa série de outros pensadores religiosos heterodoxos do século XX, como Simone Weil e seu conceito de "ateísmo purificador", ou o Eu e Tu (Ich e Du) de Martin Buber, não por acaso um kierkegaardiano.

Para Buber, há duas formas de se lidar com o mundo, incorporadas nos pronomes, em alemão, da segunda pessoa do singular ( $D u$, "Tu") e da terceira pessoa do singular, de gênero neutro ( $E s$, "Isso"), que ele chama de "palavras primárias", capazes de moldar o mundo ao serem ditas. Quando o $\mathrm{Eu}(I c h)$ diz Es, ele está apenas tendo a experiência do mundo objetivado, a atitude que, podemos observar, é típica do consumo das coisas; uma relação de fato só é estabelecida quando tratamos as "coisas" (entre aspas, porque nessa relação elas deixam de ser coisas) por $\mathrm{Du}$. Diz o autor:

The life of human beings is not passed in the sphere of transitive verbs alone. It does not exist in virtue of activities alone which have some thing for their object.

I perceive something. I am sensible of something. I imagine something. I will something. I feel something. I think something. The life of human beings does not consist of all this and the like alone.

This and the like together establish the realm of It.

But the realm of Thou has a different basis. When Thou is spoken, the speaker has no thing for his object. For where there is a thing there is another thing. Every It is bounded by others; It exists only through being bounded by others. But when Thou is spoken, there is no thing. Thou has no bounds. It is said that man experiences his world. What does that mean?

[...]

The man who experiences has no part in the world. For it is "in him" and not between him and the world that the experience arises.

The world has no part in the experience. It permits itself to be experienced, but has no concern in the matter. For it does nothing to the experience, and the experience does nothing to it.

As experience, the world belongs to the primary word I-It.

The primary word I-Thou establishes the world of relation (BUBER, 1937, p. 4-6).

O Es (It) cria coisas e tem limites, formados por outras coisas, enquanto o $D u$ (Thou) é ilimitado. Quando trato alguém por $D u$, eu reconheço o sujeito singular (infinito) que se apresenta diante de mim e não apenas uma soma de características a serem vivenciadas, como os detalhes do seu corpo ou a sua voz. Mas a questão é 
mais complexa ainda, porque não existe $D u$ nem Es sem um sujeito Ich pressuposto, e assim se formam as duplas Ich-Du e Ich-Es. Só que o Ich da experiência (Ich$E s)$ e o Ich da relação (Ich-Du) não são a mesma coisa: a experiência objetificante objetifica o próprio sujeito, e é apenas pelo $\mathrm{Du}$ que o ser humano se torna um Ich (BUBER, 1937, p. 28).

Toda a arte também, para Buber, deriva da palavra primária, o $D u$ que precisa ser dito com toda a completude do ser - a obra, porque não existe ainda, não permite que o Eu relaxe e habite o mundo do $E s$, ela urge a sua criação. $\mathrm{E}$, por mais que o resultado, a obra de arte, seja um $E s$, uma coisa entre outras coisas, por vezes ela é capaz de encarar o "contemplador receptivo em sua forma incorporada plena" (ibid., p. 10), o que quer dizer, como um $\mathrm{Du}$. Qualquer semelhança com as noções de Kierkegaard, tais como glosadas por Golomb, certamente não é acidental: o eterno $D u$, aquele que jamais virá a se tornar um $E s$, como costuma acontecer quando as relações inevitavelmente terminam, é Deus, que se faz presente em todas as instâncias de relações.

As ideias de Buber, portanto, por mais que muito posteriores à obra de Kierkegaard, nos são úteis para entendermos a relação entre a autenticidade do "eu" e os seus dotes criativos que podem culminar na criação de (uma relação com) Deus. Daí que, para Golomb, haja um grau de originalidade envolvido no processo de buscar a autenticidade:

Whereas the most passionate lover is only forming passion in his inwardness and directing it to an already existing individual, the 'knight of faith' creates first the object of his faith and then the passion involved in the faithful commitment to this object. Thus the intimate correlation between the 'how' of faith and its 'what' is entirely of his making. Therefore it is only this formative relation that can create the self's authenticity. To create one's own self, one must first overcome one's sensual nature (aesthetics), then universal reason; only then can one become what one intrinsically is: the sole creator of one's self and God. For this the utmost passion, commitment and self-overcoming are needed (GOLOMB, 1995, p. 63).

E há mais um outro elo entre a criatividade e a autenticidade na medida em que, porque a autenticidade real não pode ser cobrada, nem mesmo ensinada ou imposta sobre as pessoas, as formas filosóficas mais cristalizadas, como o ensaio ou o tratado, são inadequadas. Há limites para a persuasão racional (GOLOMB, 1995, p. 45), sobretudo quando se trata de sair da esfera da reflexão para a da ação. Nisso, o uso de recursos estéticos, como o dos heterônimos e da ironia de Kierkegaard, serve não para promover um estilo de vida estético, mas para levar o leitor a procurar essa paixão inefável que o torne capaz de criar seu objeto infinito e a si mesmo.

Essa capacidade criativa (entendida como originalidade) é igualmente louvada por Nietzsche, outro autor que, como 
Kierkegaard, também se valeu de formas literárias como o aforismo, a poesia e a narrativa para tratar do assunto. Como Golomb lembra (GOLOMB, 1995, p. 68), o filósofo nunca utilizou nenhum equivalente alemão à palavra "autenticidade" em seus escritos, mas é possível identificar um uso sistemático dos termos Warheit e Warhaftigkeit ("verdade" e "veracidade") com um sentido próximo ao eigentlich heideggeriano, que costuma ser traduzido na literatura existencialista posterior como "autêntico". Essa "veracidade", diz o comentador, só pode ser atingida se aceitarmos a vida em toda sua crueza e "imanência", i.e. rejeitando qualquer ideia de que este mundo aponte para outro mundo mais "valioso" ou mais "verdadeiro". Como vimos com o nosso exemplo da Genealogia, a questão do sofrimento ocupa um lugar central dentre as preocupações recorrentes do pensamento nietzschiano - desde o seu começo, inclusive, se lembrarmos como Nietzsche, na Origem da Tragédia, enxerga o gênero trágico como uma transfiguração do sofrimento de Dioniso, como diz Deleuze (1983, p. 12), "os sofrimentos da individuação absorvidos na alegria do ser original”. Para esse sofrimento, no entanto, que seria inerente ao ágon das forças da vida, Nietzsche encontra $o$ seu modelo não em Cristo na cruz, mas em Dioniso, porque o sofrimento cristão é compreendido como transcendental: 0 que consola o cristão em seu sofrimento é a promessa de que não sofrerá mais no Outro Mundo. Essa crença, que, para Nietzsche, cheira aos piores dos crimes humanos, o "ressentimento" e a "má consciência”, só pode levar ao niilismo, à "depreciação da vida, à negação do mundo" (DELEUZE, 1983, p. 147) e abandoná-la seria um sinal de maturidade espiritual.

A imagem que aparece em Zaratustra é a das metamorfoses do espírito que, começando como um camelo, torna-se um leão e, por fim, uma criança (NIETZSCHE, 2005). Golomb interpreta essa imagem como a luta para superar a pressão imposta sobre o indivíduo por seu condicionamento externo, representada a princípio no camelo, essa besta de carga. O leão deve liberar-se do camelo para, então, no estágio de criança, adotar e assimilar conscientemente as normas morais (GOLOMB, 1995, p. 72). Deleuze também comenta essa transformação em termos semelhantes, mas com uma ênfase na criação desses novos valores:

The camel is the animal who carries: he carries the weight of established values, the burdens of education, morality and culture. He carries them into the desert, where he turns into a lion; the lion destroys statues, tramples burdens, and leads the critique of all established values. Finally, the lion must become child, that is, he who represents play and a new beginning - creator of new values and new principles of evaluation (DELEUZE, 2001, p. 53).

Mas Deleuze vai além e identifica essas metamorfoses como estágios do pensamento do próprio Nietzsche: 
quando ele começa a se libertar da influência schopenhaueriana em $\mathrm{Hu}$ mano, demasiado humano (1878) e suas continuações, até partes de A Gaia Ciência (1882), Nietzsche se torna um leão, envolvido num projeto de "crítica total", mas em Zaratustra (1883) algo estranho acontece, "uma exaltação, uma superabundância", que prefigura sua etapa final da metamorfose em criança, com sua transmutação de valores da Negação para a Afirmação (ibid., p. 60). A afirmação da vida é uma das preocupações da fase madura da obra de Nietzsche, que se opõe à ideia da chamada vida reativa, da negação. A ação é a prova da vitalidade, da saúde do Wille zur Macht, a palavra que costuma ser traduzida como "vontade de poder" ou "vontade de potência". Para colocarmos em termos muito resumidos, forças ativas criam e transformam, enquanto as forças reativas se ressentem, julgam e procuram desfazer, sufocar e envenenar o que é criado - a raiz de todo niilismo que Nietzsche observava na história da cultura ocidental desde Sócrates (DELEUZE, 1983). Daí que, como Golomb glosa, esse "poder negativo" esteja ligado à inautenticidade, sintomática de um "eu" fraco, ao qual falta poder e que ele desesperadamente procura obter para si (GOLOMB, 1995, p. 76).

A vontade de poder, portanto, ao contrário do sentido que o senso comum deriva da palavra, não significa uma vontade de ascender ao poder e utilizá-lo para tiranizar aqueles que estão abaixo, mas uma relação de forças, como explica Deleuze. O vilão, o tirano, o aristocrata e o burocrata que abusa de sua posição, que se valem da negação, não são fortes e poderosos. Mesmo que a vontade de poder possa ter a ver com a subjugação dos outros, isso é mais uma consequência do que um objetivo - por exemplo, na relação entre poetas, como compreendida por Bloom, o poeta forte subjuga, mesmo que isso não seja seu objetivo ao escrever, os poetas posteriores, em consequência de seu poder criativo. Recorrer à violência covarde, à censura, ao aprisionamento, à tortura são comportamentos típicos da reatividade que procura sufocar o indivíduo por não conseguir lidar com sua vontade de poder, portanto. Elucidando a questão da vontade de poder, Deleuze (2001) afirma o seguinte:

Whatever the complexity of a phenomenon, we can distinguish primary forces, of conquest and subjugation, from reactive, secondary forces, of adaptation and regulation. The distinction is not only quantitative but also qualitative and typological, for it is in the nature of forces to be in relation to other forces and it is in this relation that they acquire their essence or quality. The relation of force to force is called "will." That is why we must avoid at all costs the misinterpretations of the Nietzschean principle of the will to power. This principle doesn't mean (or at least doesn't primarily mean) that the will wants power or wishes to dominate. [...] The will to power, says Nietzsche, consists not in coveting or even in taking but in creating and giving (p. 72-3, grifos do autor). 
De novo, notamos a ênfase dada às capacidades criativas da vontade de poder afirmativa, que é a chave para a vida autêntica. Golomb utiliza termos semelhantes quando afirma que Nietzsche "não postula o poder contra a moralidade, mas propõe uma moralidade ativa de poder positivo que expressa uma criatividade corajosa" (GOLOMB, 1995, p. 76). Uma associação com as artes se sugere naturalmente, haja vista que o novo imperativo da originalidade levou a uma nova compreensão do artístico, não mais como imitação, mas como criação, o que se dá, para Taylor, nos seguintes termos:

If we become ourselves by expressing what we're about, and if what we become is by hypothesis original, not based on the pre-existing, then what we express is not an imitation of the pre-existing either, but a new creation (TAYLOR, 1991, p. 62).

É evidente, no entanto, que chegar a essas forças ativas não é um caminho fácil. Em oposição ao corpo, que é ativo, a própria consciência é reativa, na medida em que ela apenas "expressa a relação de forças reativas às forças ativas que a dominam" (DELEUZE, 1983, p. 41). As forças reativas triunfaram: se num primeiro momento do niilismo a vida era depreciada em prol de valores superiores, - a Bondade, a Verdade, a Justiça, Deus - a partir disso desenvolveu-se um segundo momento niilista (já contido nesse primeiro, mas desdobrado desde então) que resulta na depreciação desses valores também: se antes a essência se opunha à aparência, a essência passa a ser negada e apenas a aparência permanece, um mundo sem valores, sem sentido e sem propósito. $\mathrm{E}$ foi a cumplicidade desse niilismo, dessa "vontade de nada", com as forças reativas que permitiu que elas triunfassem (DELEUZE, 1983, p. 148). Assim sendo, é de se esperar que essa tendência à reatividade seja um obstáculo para a criação do "eu" autêntico. Nós somos, de saída, sobrecarregados com dogmas e deficiências psicológicas, como a covardia, que herdamos culturalmente e com as quais precisamos lidar no caminho para a autenticidade, via um processo de "desmascaramento", que, em Nietzsche, se dá pelo método genealógico (GOLOMB, 1995). Porque, no entanto, o ser humano tem uma tendência a se iludir, esse processo não pode ser racional. Muito pelo contrário: quando a racionalidade é aplicada à autorreflexão, ela surge como racionalização, naturalizando os processos históricos que culminam nos valores da existência inautêntica e minando a possibilidade de alternativas. De novo, somos impelidos a pensar nos papéis atribuídos à arte pela modernidade, não apenas como dissolução temporária das ansiedades, um papel tomado pelo que se entende como entretenimento hoje, mas como este espaço em que é possível exercer os poderes de autocriação. 


\section{Conclusões}

Com isso em mente, fica evidente que, no discurso da poesia moderna, é o próprio poeta quem melhor incorpora a ideia da vida autêntica. Isso pode parecer contraditório quando o pensamos em moldes kierkegaardianos mais estritos, nos quais seria mais intuitivo o encaixarmos como um personagem da vida estética (poesia=arte=estética), mas é importante lembrar que, para além das considerações sobre o uso da estética no próprio Kierkegaard ou Nietzsche para incitar o leitor à autenticidade, seu livro Ou isso, ou aquilo é de 1842, anterior tanto à consolidação da "era do capital", que se dá a partir de 1848, segundo a divisão de Hobsbawm, quanto do ponto de ruptura da poesia moderna para Steiner. E, de certa forma, na medida em que o poeta moderno precisa criar sua relação com Deus, entendido não necessariamente no sentido religioso mais estrito, mas como o que é inefável e misterioso, ele pode ser compreendido como um "cavaleiro da fé", não por acaso disposto também a viver a poesia em detrimento da vida prática inautêntica e até da moralidade. O poeta vive de forma intensa, não por ter experiências extremas - Eliot, por exemplo, em seu ensaio "Tradition and the Individual Talent", admoesta contra a procura de experiências novas e extremas como combustível da poesia (ELIOT, 1964, p. 10)-, mas por se ver num estado de ser que é ele próprio intenso, dotado de uma vasta vitalidade interior, transformando suas experiências de modo que elas nunca são banais (ver o infinito no grão de areia, etc.), por isso não podem ser descritas com a linguagem perfunctória do jornalismo, do comércio e da burocracia. Nisso, o seu dom, na forma da capacidade de criar o que é novo, o que é original, é a prova da sua autenticidade.

Mas há um segundo movimento ainda. Não basta, para o poeta, buscar ser autêntico e ostentar sua autenticidade. Os leitores não apenas leem e absorvem o conteúdo semântico e a musicalidade do poema moderno, admirando golpes de gênio como uma imagem nova aqui $\mathrm{e}$ ali ou um witticism interessante, como quem assiste a um desfile. A dificuldade desses poemas leva o leitor a se engajar com eles de outros modos, porque parece que o poema chega incompleto - fragmentos e destroços, como diz Steiner. Seus silêncios estão grávidos de significado em potencial. Porém, para o leitor desavisado, essa poesia pode parecer absurda, nonsense, não-poesia, como se o poeta tivesse escrito "qualquer coisa" $\mathrm{e}$ chamado de poema como piada. É apenas ao superar essa resistência inicial e tratar do poema como um espaço no qual o sentido é construído pela interação ativa com o leitor, que passamos a ler o poema de fato. O poema moderno, quanto mais arquetípico de sua modernidade, menos vai nos dizer, preferindo deixar as coisas 
"no ar" para serem captadas pelo leitor, mesmo que isso leve leitores diferentes a conclusões díspares - afinal, cada leitor é um indivíduo singular e preencherá essas lacunas com sua própria experiência.

Um poema como "The sick rose", de Blake (1988, p. 23), pode ser compreendido como antecessor e ilustrativo das dificuldades modernas, para darmos um exemplo. Datado de 1794, por mais que seja anterior à data de ruptura de Steiner e cada verso individual seu seja uma enunciação possível e clara da língua inglesa, o poema em si, como um todo, é obscuro o suficiente para precisar de um esforço ativo por parte da imaginação do leitor para "ligar os pontos". Em seus oito versos, o poeta descreve a relação amorosa doentia entre uma rosa e o verme invisível que voa pela noite, a desvela e a destrói. Porque Blake nunca explica o que essa imagem simboliza, apenas evocando uma atmosfera sexual destrutiva, sem explicitar nada, diferentes críticos chegam a diferentes conclusões. S. Foster Damon, por exemplo, projeta uma visão alegórica cristianizada sobre o poema, como se a rosa fosse o amor puro e casto, que é destruído pelo desejo da carne, na forma do verme (DAMON, 1924). Bloom enxerga nele um comentário sobre os rituais sociais, nos quais se espera das mulheres uma postura pudica, que se ocultem e ajam como se fugissem ao sexo, enquanto os homens as perseguem, o que cria uma dinâmica des- trutiva pela qual o sexo só pode ser uma violação (BLOOM, 1971). Para Camille Paglia, a rosa é uma imagem masturbatória, autossuficiente em seu autoerotismo solipsista, por mais perverso e estéril que seja, temendo a comunhão do sexo porque acredita que apagaria sua identidade - uma imagem representativa da atitude ambivalente do próprio Blake quanto ao sexo (PAGLIA, 1992). E assim por diante. Nada está explícito em "The sick rose", mas tudo está lá em algum grau. Ler um poema enigmático não significa desvendá-lo, - não é uma adivinhação do tipo "o que é, o que é?" - mas produzir um novo texto a partir dele, num envolvimento que não é tanto lógico e racional quanto criativo.

É assim que se chega à conclusão, como a de Bloom (1973, p. 95), de que a leitura de todo poema (moderno) resulta num outro poema. Essas leituras não se entendem mais como científicas, como era a pretensão dos formalistas e estruturalistas, mas uma outra coisa, fruto de um processo criativo.

O poeta então instiga o leitor pela via indireta, rumo ao caminho da autenticidade. Se o poeta é autêntico e seus poemas geram novos poemas em sua leitura, seus leitores acabam se tornando poetas sem se darem conta disso - logo, também chegam a um vislumbre do que seria a experiência autêntica pela linguagem, com a qual são estimulados a interagir de novas formas que não o seu uso prá- 
tico e perfunctório. O leitor é levado a lidar não apenas com o significado das palavras ou seu uso cotidiano, mas os detalhes de suas conotações, a sonoridade, as imagens que a palavra evoca e a rede de signos na qual ela se insere, as tensões internas a cada palavra e entre as palavras que a cercam. Mesmo outras palavras que não estão no texto acabam se insinuando ao leitor, chamando sua atenção e se revelando importantes para a leitura. Somos obrigados a assumir uma outra postura diante da linguagem, que é a postura que o poeta também nos pede que seja assumida diante do mundo, no qual as palavras, como as coisas, são desfamiliarizadas. Isso é um lugar-comum, mas precisa ser repetido, porque, para o poeta, é esse processo que desperta o indivíduo do sonambulismo do hábito e abre o caminho para a experiência (ou relação, para usarmos o vocabulário de Buber) singular da poesia.

No mais, o gesto de escrever é o que firma o poeta como uma figura autêntica, porque estabelece uma relação com o outro: é somente com a participação na sociedade e com a ação que a autenticidade é possível, em oposição ao solipsismo, ao narcisismo e à reflexão estéril (GOLOMB, 1995; TAYLOR, 1991). Não podemos falar nesses termos, de autenticidade, sobre um poeta, por exemplo, que não escreva - por mais autocentrado que seja o seu discurso, o ato de escrever sempre pressupõe um leitor, ainda que, como Taylor lembre, possa ser um leitor futuro, um público ainda não criado. $O$ escritor-poeta e o leitor-feito-poeta são unidos, portanto, nesse gesto e vislumbram juntos as possibilidades autênticas da linguagem e da vida.

Num outro nível ainda, existe um ponto em que as aproximações entre poesia e misticismo fazem todo o sentido, mais do que se poderia imaginar a partir do nível superficial da mera adoção do discurso inspirado pelo misticismo: na atividade mística, como visto com Scholem e James, nenhum conteúdo linguístico é de fato recebido. Como vimos, essa experiência é, em essência, amorfa, e, por isso, sempre um desafio para os místicos expressá-la em palavras. Igualmente, no poema moderno arquetípico, apesar da superfície textual, é raro que o que é transmitido seja um conteúdo linguístico, informacional - o "conteúdo inessencial” de que fala Benjamin. O que é essencial está além da linguagem, o que fica claro quando vemos que o poema não pode ser parafraseado. Mesmo suas explicações não são paráfrases - assim como com explicações de piadas, o efeito principal se perde -, apenas um tipo de andaime para catalisar a experiência. $\mathrm{E}$ é assim que, ainda que ostensivelmente um objeto verbal, o poema moderno é uma máquina de transmissão de conteúdos não-verbais, tal como é a experiência mística. 
Como se pode observar via Golomb e Taylor, dado o cenário espiritualmente desolador da modernidade, desencantada e desprovida de sentido, a capacidade da vida autêntica de criar sentido para si acaba se tornando um valor de salvação, conforme nos tornaria "mais humanos" num mundo desumanizado, na medida em que 0

[...] mero desejo de viver de forma genuína, a mera tentativa de tornar-se autêntico expressa a determinação corajosa de não desesperar-se ou se render aos processos poderosos de nivelamento, objetificação e despersonalização (GOLOMB, 1995, p. 146).

Nesse discurso, a vida autêntica - ou, pelo menos, a busca pela autenticidade - emerge como a única vida possível de ser vivida. Todas as outras possibilidades parecem mais fáceis e menos genuínas, porque incluem a adesão a valores pré-fabricados e a aceitação dos processos de desumanização e despersonalização do indivíduo, que o reduzem, no limite, a uma peça mecânica, uma engrenagem numa máquina. Taylor faz uma declaração semelhante quando afirma que, dentro do problema da autenticidade,

I am called upon to live my life in this way, and not in imitation of anyone else's. But this gives a new importance to being true to myself. If I am not, I miss the point of my life, I miss what being human is for me (TAYLOR, 1991, p. 29).

No campo da linguagem, os poetas e afins são as figuras que reconhecem as forças responsáveis pela "nivelação, objetificação e despersonalização" do mundo, em seu modo de manejar os discursos do comércio e da burocracia, e se propõem a combatê-los nessa arena. Daí que, como aponta Tezza (2003), em sua análise dos discursos dos próprios poetas sobre a poesia, emerja a noção de poesia como resistência, que também é compartilhada por alguns pensadores como Adorno, segundo Perloff (2013, p. 40), a resistência de quem realiza uma tarefa entendida como mística, sacerdotal, xamânica (às vezes de forma bastante literal). E é ao assumi-la que o poeta justifica sua existência na modernidade, pois o bloqueio completo da fagulha dos poderes criativos humanos, segundo essa narrativa, resultaria na catástrofe da desumanização generalizada. Isso permite que ele continue servindo à sociedade, à sua maneira, mesmo enquanto assume uma postura de resistência e rejeição.

\section{The experience of intense being in modern poetry and the search for authentic life}

\section{Abstract}

the present paper takes as its starting point reflections on modern western poetry as an art whose strong features are the intensity of the singular experience and an agonic struggle against the limits of language which impose obstacles to the communicability of that experience. By approximations to mystic discourse, the mystic being the prototypical 
character of contact with the ineffable, and the thought of Kierkegaard and Nietzsche on the concept of authentic life, it intends to show how the difficulties, obscurities and complexities of such a silent, fragmentary, enigmatic kind of poetry are aligned, even if not expressly so, to a discourse that promotes authenticity through linguistic experience.

Keywords: Authenticity. Kierkegaard. Nietzsche. Modernity. Mysticism.

\section{Referências}

ANDRADE, Carlos Drummond de. A Rosa do Povo. Rio de Janeiro: Record, 2001.

BALAKIAN, Anna. O Simbolismo. São Paulo: Perspectiva, 1985.

BENJAMIN, Walter. A tarefa-renúncia do tradutor. Tradução de Susana Kampff Lages. In: BRANCO, Lucia Castello (org.) A tarefa do tradutor, de Walter Benjamin: quatro traduções para o português. Belo Horizonte: Fale/UFMG, 2008.

BLAKE, William. Complete Poetry and Prose of William Blake. Berkeley: University of California Press, 2008.

BLOOM, Harold. The Visionary Company: A Reading of English Romantic Poetry. Ithaca \& Londres: Cornell UP, 1971.

BLOOM, Harold. The anxiety of influence: $a$ theory of poetry. Nova York: Oxford UP, 1973.

BUBER, Martin. I and Thou. Tradução de Ronald Gregor Smith. Edimburgo: T. \& T. Clark, 1937.

DAMON, S. Foster. William Blake: His Philosophy and Symbols. Nova York: Houghton Mifflin, 1924.

DELEUZE, Gilles. Nietzsche and Philosophy. Tradução de Hugh Tomlinson. Nova York: Columbia UP, 1983.
DELEUZE, Gilles; GUATTARI, Félix. L'anti-Oedipe: Capitalisme et schizophrénie. Paris: Les Editions de Minuit, 1972.

ELIOT, Thomas Sterns. "Tradition and the Individual Talent”. In: Selected Essays of T. S. Eliot. Nova York: Harcourt, Brace, and World, 1964.

GOLOMB, Jacob. In Search of Authenticity: From Kierkegaard to Camus. Nova York: Routledge, 1995.

HOBSBAWM, Eric. The Age of Revolution (1789-1848). Nova York: Vintage Books, 1962.

JAMES, William. The Varieties of Religious Experience: a Study in Human Nature. Being the Gifford Lectures on Natural Religion Delivered at Edinburgh on 1901-1902. Nova York: Longmans, Green, and Co., 1917.

JENKINS, Richard. Disenchantment, Enchantment and Re-Enchantment: Max Weber at the Millennium. Max Weber Studies, Londres, No. 1, pp. 11-32, 2000

KIERKEGAARD, Søren. Ou isso, ou aquilo: um fragmento da vida. São Paulo: Abril Cultural, 1979.

LERNER, Ben. The Hatred of Poetry. Nova York: Random House, 2016.

LYNCH, Jack. The Perfectly Acceptable Practice of Literary Theft: Plagiarism, Copyright, and the Eighteenth Century. 2006. Disponível em: http://www.writing-world. com/rights/lynch.shtml. Acesso em: 5 jun. 2018.

MCINTOSH, Christopher. Eliphas Lévi and the French Occult Revival. Albany: State University of New York Press, 2011.

NIETZSCHE, Friedrich. Assim falou Zaratustra. Tradução de Heloisa da Graça Burati. São Paulo: Rideel, 2005.

PAGLIA, Camille. Personas sexuais: arte e decadência de Nefertite a Emily Dickinson. Tradução de Marcos Santarrita. São Paulo: Companhia das Letras, 1992. 
PERLOFF, Marjorie. O Gênio Não Original: poesia por outros meios no novo século. Trad. Adriano Scandolara. Belo Horizonte: Editora da UFMG, 2013.

SCHOLEM, Gershom. A Cabala e seu simbolismo. Tradução de Hans Borger e J. Guinsburg. São Paulo: Perspectiva, 1978.

SCHLUCHTER, Wolfgang. The Rise of Western Rationalism: Max Weber's Developmental History. Trad. de Guenther Roth. Berkeley, CA: University of California Press, 1981.

STEINER, George. After Babel: aspects of language and translation. Nova York: Oxford UP, 1975.

TAYLOR, Charles. The Ethics of Authenticity. Cambridge, MA: Harvard UP, 1991.

TEZZA, Cristóvão. Entre a Prosa e a Poesia: Bakhtin e o Formalismo Russo. Rio de Janeiro: Rocco, 2003.

TRILLING, Lionel. Sincerity and Authenticity. The Charles Eliot Norton Lectures, 19691970. Cambridge, MA: Harvard UP, 1971.

VEYNE, Paul. A Elegia Erótica Romana: O amor, a poesia e o Ocidente. São Paulo: Brasiliense, 1985.

WEBER, Max. A ética protestante e o espírito do capitalismo. Companhia das Letras, São Paulo, 2004.

YOUNG, Edward. Edward Young's Conjectures on Original Composition. Edição de Edith J. Morley. Londres: Longmans, Green \& Co., 1918. 